\title{
СИНТЕЗ ВЫСОКОЭНЕРГЕТИЧЕСКИХ МАТЕРИАЛОВ, МОДИФИЦИРОВАННЫХ НАНОРАЗМЕРНЫМ УГЛЕРОДОМ, И ИССЛЕДОВАНИЕ ИХ ЧУВСТВИТЕЛЬНОСТИ К ЛАЗЕРНОМУ ИЗЛУЧЕНИЮ
}

\author{
Ю.Н. Ведерников ${ }^{1}$, С.А. Федотов ${ }^{1}$, А.В. Смирнов ${ }^{1}$, Г.А. Аватинян ${ }^{2}$, \\ Ю.Г. Паршиков ${ }^{2}$ А.Н. Пономарев ${ }^{3}$ Ю.А. Кулагин ${ }^{4}$
}

\begin{abstract}
${ }^{1}$ Акционерное Общество «Научно-производственное предприятие «Краснознаменец», ул. Челябинская, 95, г. Санкт-Петербург, Российская Федерация, 195043

E-mail: vedjrnik@mail.ru, serge-fedotov-1971@mail.ru, smirnov157@yandex.ru

${ }^{2}$ Федеральное государственное бюджетное учреждение науки Межведомственный центр аналитических исследований в области физики, химии и биологии при Президиуме Российской академии наук (МЦАИ РАН), ул. Профсоюзная, 65, с.6, г. Москва, Российская Федерация, 117342

E-mail: agra89@mail.ru, parshikov62@ rambler.ru

${ }^{3}$ Акционерное Общество «НТЦ Прикладных Нанотехнологий», Алтайская ул., 7, литер Б, г. Санкт-Петербург, Российская Федерация, 196066

E-mail: 9293522@gmail.ru

${ }^{4}$ Государственный научный центр Российской Федерации Федеральное государственное унитарное предприятие «Центральный научно-исследовательский институт химии и механики» (ГНЦ РФ ФГУП «ЦНИИХМ»), ул. Нагатинская, д. 16а, г. Москва, 115487

E-mail: kulaginyua@mail.ru
\end{abstract}

Найдено, ито высокоэнергетические материалы (ВЭМ), модифицированные наноразмерным углеродом фуллероидного типа (астраленом), такие как: ТЭН - тетранитропентаэритрит, ТНРC - тринитрорезорцинат свинца, НКT (NCP) - перхлорат (5-нитротетразолато-N2) пентаамминкобальта (III) обладают повышенной восприимчивостью к излучению от лазерного диода. Модифицированные ВЭМ получали по оригинальным методикам: НКТ и ТЭН в процессе кристаллизации в суспензии астралена, а модифицированный ТНРС непосредственно при синтезе в присутствии наночастиц астралена. Наиболее эффективным способом разделения астраленовых кластеров является их диспергирование при интенсивном воздействии ультразвука в жидкой среде при удельной мощности излучения не менее $2-4 \mathrm{Bm} / \mathrm{cm}^{3}$. В соответствии с этим для обеспечения наноразмеров астрален обрабатывали ультразвуком в изопропиловом спирте или водном изопропиловом спирте и использовали в виде суспензии для получения модифицированных ВЭМ. Для испытаний использовалась система лазерного инициирования на основе лазерного диода на нескольких излучающих кристаллах с длиной волны излучения 976 нм, максимально допустимой выходной мощностью излучения в непрерывном режиме $60 \mathrm{Bm}$ и выводом излучения в оптоволокно с диаметром сердцевины 105 мкм с числовой апертурой 0,15. После снаряжения экспериментального образца лазерного капсюля-детонатора (ЛКД), светочувствительными ВЭМ, производилась установка в его корпус оптоволоконного кабеля, состоящего из инициирующего оптоволокна диаметром 105 мкм и регистрирующего волокна диаметром 500 мкм, имеющих полированные торцы и общую концевую колодку. Проведены испытания составов в макете ЛКД при разных значениях мощности излучения лазерного диода, определен порог плотности мощности излучения для ВЭМ как модифицированных астраленом, так и штатных одинаковой дисперсности. Получено, что введение астраленов в ВЭМ способствует значительному увеличению чувствительности к лазерному излучению не только за счет поглощения квантов излучения наночастицами астралена с образованием "горячих точек", но и со специфическим механизмом, свойственным для фуллероидных наночастиц: реакции получения синглетно-возбуждённого кислорода.

Ключевые слова: лазерное инициирование, лазерный диод, астрален, синглетно-возбуждённый кислород, высокоэнергетические модифицированные материалы 


\title{
SYNTHESIS OF HIGH-ENERGY MATERIALS MODIFIED WITH NANOSIZED CARBON AND INVESTIGATION OF THEIR SENSITIVITY TO LASER RADIATION
}

\author{
Yu.N. Vedernikov ${ }^{1}$, S.A. Fedotov ${ }^{1}$, A.V. Smirnov ${ }^{1}$, G.A. Avatinyan ${ }^{2}$, \\ Yu.G. Parshikov ${ }^{2}$, A.N. Ponomarev ${ }^{3}$, Yu.A. Kulagin ${ }^{4}$
}

\begin{abstract}
${ }^{1}$ Joint-stock company «Science and Production Enterprise «Krasnoznamenets», Chelyabinskaya str., 95, SaintPetersburg, Russian Federation, 195043

E-mail: vedjrnik@mail.ru, serge-fedotov-1971@mail.ru,smirnov157@yandex.ru

${ }^{2}$ Federal State State-financed Institution of Sciences Interdepartmental Center of Analytic Studies in the Sphere of Physics, Chemistry and Biology under Presidium of Russian Academy of Sciences (ICAS RAS), 65 Trade Union Street, p. 6, Moscow, Russian Federation, 117342

E-mail: agra89@mail.ru, parshikov62@ rambler.ru

${ }^{3}$ Joint-stock company «Science and Technic Center of Applied Nanotechnologies», Altayskaya str., 7, letter B, Saint-Petersburg, Russian Federation, 196066

E-mail: 9293522@gmail.ru

${ }^{4}$ The Central Scientific Research Institute of Chemistry and Mechanics, Nagatinskaya str., 16a, Moscow, Russian Federation, 115487

E-mail: kulaginyua@mail.ru
\end{abstract}

It was found that high-energy materials (HEM) modified with nanosized fulleroid carbon (astralen), such as: PETN - pentaerythritol tetranitrate, LS - lead styphnate, NCP - pentaammine(5nitro-2H-tetrazolato-N2)cobalt (III) perchlorate had an increased susceptibility to the laser diode beam. Modified HEM was obtained by original methods: NCP and PETN during crystallization in a suspension of astralen, and modified LS directly during synthesis in the presence of astralen nanoparticles. The most effective way to separate astralenic clusters is to disperse them under intense exposure to ultrasound in a liquid medium at a specific radiation power of at least $2-4 \mathrm{~W} / \mathrm{cm}^{3}$. According to it, to obtain nanosize, astralen was sonicated in isopropyl alcohol or aqueous isopropyl alcohol and used as a suspension to obtain modified HEM. For the tests we used a laser initiation system based on a laser diode on several emitting crystals with a radiation wavelength of $976 \mathrm{~nm}$, a maximum permissible output radiation power in a continuous mode of $60 \mathrm{~W}$, and radiation output into an optical fiber with a core diameter of $105 \mu \mathrm{m}$ and a numerical aperture of 0.15. After equipping the experimental sample of the laser capsule-detonator (LCD) with photosensitive HEMs, a fiber-optic cable was installed in its body, consisting of initiating optical fiber with a diameter of $105 \mu \mathrm{m}$ and a recording fiber with a diameter of $500 \mu \mathrm{m}$, each having polished ends and a common end block. The compositions were tested in the LCD model at different values of the laser diode radiation power, the threshold of the radiation power density for HEMs, both modified with astralen and standard ones of the same dispersion, was determined. It was found that the introduction of astralenes into HEM contributed to a significant increase in sensitivity to laser radiation not only due to the absorption of radiation quanta by astralen nanoparticles with the formation of "hot spots", but also with a specific mechanism characteristic of fulleroid nanoparticles: the reaction of obtaining singlet-excited oxygen.

Key words: laser initiation, laser diode, astralene, singlet-excited oxygen, high-energy modified materials

Для цитирования:

Ведерников Ю.Н., Федотов С.А., Смирнов А.В., Аватинян Г.А., Паршиков Ю.Г., Пономарев А.Н., Кулагин Ю.А. Синтез высокоэнергетических материалов, модифицированных наноразмерным углеродом, и исследование их чувствительности к лазерному излучению. Рос. хим. ж. (Ж. Рос. хим. об-ва). 2021. Т. LXV. № 3. С. 25-32

For citation:

Vedernikov Yu.N., Fedotov S.A., Smirnov A.V., Avatinyan G.A., Parshikov Yu.G., Ponomarev A.N., Kulagin Yu.A. Synthesis of high-energy materials modified with nanosized carbon and investigation of their sensitivity to laser radiation. Ros. Khim. Zh. 2021. V. 65. N 3. P. 25-32 


\section{ВВЕДЕНИЕ}

Применение систем инициирования с лазерным воздействием позволяет существенно повысить технологичность и безопасность работ, что обуславливается высоким уровнем стойкости к электромагнитным полям и разрядам статического электричества, поскольку в оптическом диапазоне, как правило, отсутствуют случайные источники с мощностью, достаточной для подрыва детонатора, использующего светочувствительный состав. Практическая реализация лазерных детонаторов в технических взрывных устройствах в настоящее время связана с применением полупроводниковых лазерных диодов с малыми габаритами и небольшой мощности, что не позволяет использовать в конструкции изделия штатные бризантные взрывчатые вещества (БВВ) и даже инициирующие ВВ (ИВВ) с малым временем срабатывания. Высокая плотность энергии при инициировании ВВ от лазерного импульса в диапазоне спектра 0,69-1,06 мкм (диапазон практического использования лазеров при инициировании ВВ) обусловлена необходимостью скоростного нагрева непрозрачных микровключений в материале ВВ или организации светового пробоя, поскольку в видимом и ближнем ИК-спектре излучения ВВ оптически прозрачны. Оптические свойства прессованных порошков ВВ представляют для видимого и ближнего ИК-диапазона спектра, как правило, типично диффузионнорассеивающую среду с плотной упаковкой рассеивателей. Так, по оценкам различных авторов на нагрев таких ВВ расходуется менее $1 \%$ энергии инициирующего импульса. Это связано как с отсутствием резонансного механизма возбуждения молекул ВВ в данном диапазоне лазерного излучения, так и с рядом факторов, определяющих поведение ВВ в зоне инициирования. На основании существующих представлений процессов инициирования лазерным излучением $\mathrm{BB}$, основанных на том, что в основе процесса инициирования лежит разогрев отдельных поглощающих включений или других оптических неоднородностей с образованием локальных тепловых очагов, введение поглощающих примесей способствует образованию дополнительных центров разогрева. В качестве таких поглощающих добавок к порошкообразному ВB известно использование тонкодисперсных металлических порошков, графита, сажи. Введение таких добавок в ВВ приводит к увеличению коэффициента поглощения [1]. Однако, это приводит к незначительному уменьшению порога плотности энергии инициирования, а в некоторых случаях приводит даже к увеличению плотности энергии. При их значительном введении заметно уменьшается коэффициент отражения, что приводит к падению освещенности включений, в силу чего резко увеличивается порог инициирования [2]. Модификация поверхности кристаллов энергетических материалов (ЭМ) - эффективный путь целенаправленного изменения их целевых свойств.

Известно положительное использование наночастиц (100-120 нм) алюминия вводимых в ТЭН для увеличения восприимчивости к одиночному импульсу неодимового лазера [3]. Максимальная чувствительность и максимальное давление продуктов взрыва достигается при массовой концентрации наночастиц алюминия $0,1 \%$. Чувствительность смеси увеличивается до 100 раз относительно образцов, не содержащих наночастиц. Данный эффект связан с поглощением излучения непосредственно наночастицами с образованием «горячих точек», что приводит к инициированию экзотермической реакции в основном веществе. Недостатком данного состава является нестабильность свойств алюминия со временем, образование окиси алюминия и потеря чувствительности.

Известны многие вещества, которые можно отнести к наноуглеродам (НУ): наносажа, нанотрубки, фуллерены, ультрадисперсные алмазы детонационного синтеза, астралены и др. Однако, совсем не все наноуглероды являются сенсибилизаторами, повышающими чувствительность к лазерному излучению. Так, например, высшие фуллерены более $\mathrm{C}_{70}\left(\mathrm{C}_{78}, \mathrm{C}_{84}\right)$ имеют область оптического взаимодействия (поглощения) в области красного и ближнего ИК спектра, а для $\mathrm{C}_{60}$ она составляет 400-700 нм [4]. В связи с этим, важным этапом работ по изучению процессов инициирования взрывного разложения энергонасыщенных материалов является исследование влияния добавок НУ на его чувствительность к воздействию широко применяемого в науке и технике когерентного светового излучения.

В качестве наномодификатора нами был выбран астрален, а в качестве ВЭМ были использованы ТНPC, НКТ (NCP), ТЭН.

Астрален представляет собой углеродные наночастицы фуллероидного типа с межслоевым расстоянием 0,34-0,36 нм, имеющие тороидальную форму с соотношением внешнего диаметра к толщине многослойного тора (10-3):1, имеющим средний размер 15-100 нм [5]. Астралены, как и фуллерены, являются фотосенсибилизаторами синглетно-возбужденного кислорода под действием ла- 
зерного излучения. Они относятся к высокоупорядоченным кластерам углерода со смешанной гибридизацией орбиталей $\left(\mathrm{sp}^{3}-\mathrm{sp}^{2}\right)$. Их можно объединить общим термином - фуллероиды или фуллероидные наночастицы. Делокализация валентных электронов в рамках отдельного кластера в целом - основное их отличие от всех остальных гомологов углерода. Система разрешенных триплетных и синглетных состояний - разветвлённая, и при этом первое триплетное состояние имеет значение 1,63 эВ, что совпадает со значением энергии метастабильного синглетного состояния двухатомного кислорода и создаёт условия для трансферта энергии возбуждения от фуллероидов к кислороду, и является способом получения синглетно-возбуждённого кислорода при высоких уровнях воздействия электромагнитного излучения. Возбуждённый таким образом молекулярный кислород через люминесценцию практически сразу же переходит в высокостабильное синглетное состояние $\mathrm{O}_{2}\left(\mathrm{a}^{1} \Delta_{\mathrm{g}}\right)$ с энергией 0,98 эВ. При этом его время жизни измеряется десятками и сотнями миллисекунд [6-10], чего вполне достаточно для участия в реакциях окисления ВВ со значительно большей кинетической эффективностью, чем могут обеспечить известные формы активного кислорода (атомарный кислород и озон). Использование астраленов является более выгодным, чем фуллеренов. Высшие фуллерены практического значения не имеют и вряд ли будут иметь в будущем, поскольку все фуллерены - это синтетические формы углерода. Так, например, фуллерена $\mathrm{C}_{60}$ в фуллереновой саже при её синтезе содержится 7-10\% от массы сажи, а высших фуллеренов $\left(\mathrm{C}_{70}\right.$ и более $)$ - не более $0,15 \%$, и их выделение - крайне неэффективный процесс. Астралены отличаются от фуллеренов (0,67-0,70 нм), помимо прочего, более значительными размерами (5-150 нм) и, соответственно, обладают гораздо большими количествами полусвязанных и полусвободных делокализованных валентных электронов (до нескольких миллионов, против 60 у фуллерена $\mathrm{C}_{60}$ ), что позволяет существенно увеличить выход фотохимической реакции получения синглетно-возбуждённого кислорода.

\section{МЕТОДИКА ЭКСПЕРИМЕНТА}

Материалы и методы. Использовались химически чистые реактивы и растворители без предварительной очистки и обезвоживания. Измельчение кластеров модификатора до наноразмера проводили действием ультразвука на установке ИЛ100-6/4 мощностью 2500 Вт с рабочей частотой около 23 кГц. Осаждения ВЭМ проводили в стеклянном стакане при перемешивании пропеллерной мешалкой.

Синтез астралена. Тороидальные многослойные углеродные наночастицы фуллероидного типа получены путем селекции размеров и форм многослойных углеродных наночастиц разделением их в электрическом поле, как это описано в работе Броздниченко А.Н. и др. [11]. Для получения наночастиц указанной формы в вакуумный объем помещают катодную пластину, на которой размещены полученные окислением в результате предыдущих операций многослойные углеродные наночастицы и, параллельно ей, анодную пластину, выполненную из немагнитного материала, например, тантала. После подключения анода и катода к источнику высокого напряжения подают питание и постепенно повышают разность потенциалов, действующую в межэлектродном промежутке. При достижении напряженности поля в 8001000 B/мм начинает появляться автоэмиссионный ток. При увеличении автоэмиссионного тока возникает сила притяжения анода катодом, что фиксируется вакуумным динамометром, на котором закреплена анодная пластина. Начиная с некоторого значения автоэмиссионного тока, часть многослойных углеродных наночастиц перемещается с катода на анод, при этом сила, действующая в межэлектродном промежутке, перестает расти. Затем напряжение, поданное на катод и анод, снимают, вакуумный объем заполняют инертным газом и собирают углеродные многослойные наночастицы, накопившиеся на анодной пластине. Многослойные углеродные наночастицы, выделенные таким образом, имеют тороидальную форму с соотношением внешнего диаметра к толщине тела тора, равным (10-3):1, как показали исследования, выполненные с помощью просвечивающего электронного микроскопа JEM-100C [5].

Модифицированные ВЭМ получали по оригинальным методикам: НКТ и ТЭН в процессе кристаллизации в суспензии астралена, а модифицированный ТНРС (ТНРС-М) непосредственно при синтезе в присутствии наночастиц астралена.

Необходимо отметить, что практическая работа с астраленами крайне осложнена их склонностью к слипанию. Наиболее эффективным способом разделения астраленовых кластеров является их диспергирование при интенсивном воздействии ультразвука в жидкой среде при удельной мощности излучения не менее $2-4 \mathrm{BT} / \mathrm{cm}^{3}[12]$. В соответствии с этим для обеспечения наноразмеров 
модификатор обрабатывали ультразвуком в изопропиловом спирте или водном изопропиловом спирте и использовали в виде суспензии для внедрения в ВЭМ.

Взрывчатый состав на основе перхлората(5нитротетразолато- $\left.N^{2}\right)$ пентаамлинкобальта. НКТ растворили при температуре $80-85^{\circ} \mathrm{C}$ в дистиллированной воде, подкисленной хлорной кислотой. В реакционный стакан с мешалкой, установленный в водяную баню, залили суспензию астралена в изопропаноле. В охлажденную смесь при перемешивании прилили горячий раствор НКТ таким образом, чтобы температура реакционной массы не превышала $50{ }^{\circ} \mathrm{C}$. По окончании слива раствора НКТ смесь охладили до $20^{\circ} \mathrm{C}$, реакционную массу отфильтровали на вакуум-воронке. Продукт на фильтре промыли спиртом и сушили в сушильном шкафу при $60^{\circ} \mathrm{C}$ в течение 4 ч. Выход состава $85-90 \%$.

Взрывчатый состав на основе ТЭНа. Раствор ТЭНа в ацетоне влили в перемешиваемую суспензию астралена в смеси изопропанола с водой (1:1 об.). Дали выдержку в течение 5 минут, после чего осадок отделили на вакуум-воронке и сушили в сушильном шкафу при температуре $60^{\circ} \mathrm{C}$ в течение 6 ч. Выход состава 85-95\%.

Взрывчатый состав на основе ТНРС. Приготовили $4 \%$ водный раствор стифната натрия из стифниновой кислоты и гидрокарбоната натрия при $70{ }^{\circ} \mathrm{C}$, полученный раствор подкислили уксусной кислотой. Приготовили раствор нитрата свинца концентрацией $15 \%$ с избытком $18 \%$ от стехиометрического количества.

К суспензии астралена в смеси изопропанола с водой (1:1 об.) при интенсивном перемешивании добавили растворы нитрата свинца и стифната натрия. После выдержки образовавшиеся кристаллы отделили на вакуум-воронке, промыли на фильтре холодной водой и спиртом. Продукт сушили в сушильном шкафу в течение 6 ч при $60^{\circ} \mathrm{C}$. Выход продукта 35-45\%.

\section{РЕЗУЛЬТАТЫ И ИХ ОБСУЖДЕНИЕ}

Испытания на чувствительность к лазерному излучению. Для испытаний использовалась система лазерного инициирования на основе лазерного диода на нескольких излучающих кристаллах с длиной волны излучения 976 нм, максимально допустимой выходной мощностью излучения в непрерывном режиме 60 Вт и выводом излучения в оптическое волокно с диаметром сердцевины 105 мкм с числовой апертурой 0,15 .
После снаряжения экспериментального образца ЛКД, светочувствительными ВЭМ, производилась установка в его корпус оптоволоконного кабеля, состоящего из инициирующего оптоволокна диаметром 105 мкм и регистрирующего волокна диаметром 500 мкм, имеющих полированные торцы и общую концевую колодку. Установка оптоволоконного кабеля (оптического ввода) производилась вплотную к поверхности оптического подпора светочувствительного заряда ЛКД. Для исключения контакта между световодами и поверхностью ВВ между ними устанавливался оптический подпор из фторопласта при этом диаметр светового пятна на поверхности ВВ согласно [13] составлял около 126 мкм. После установки кабеля производилась фиксация колодки кабеля в корпусе гильзы путем обжатия с использованием цанговой обжимки.

Экспериментальный образец ЛКД размещался в защитной камере на свинцовой пластине толщиной 4 мм на подставке для оценки инициирующей способности. После закрытия защитной камеры транспортный световод, подключенный к СЛИ, через оптический соединитель (коннектор) 12 подсоединяется к инициирующему световоду 2 , а регистрирующий световод $\mathbf{3}$ к фотодиоду $\mathbf{4}$ для регистрации вспышки состава по электрическому сигналу, генерируемому фотодиодом. При этом второй фотодиод, установленный внутри защитной камеры 7, служил для регистрации срабатывания ЛКД и выдавал электрический сигнал от вспышки продуктов детонации, прорывающихся сквозь корпус ЛКД. Измерительная схема испытаний представлена на рис. 1.

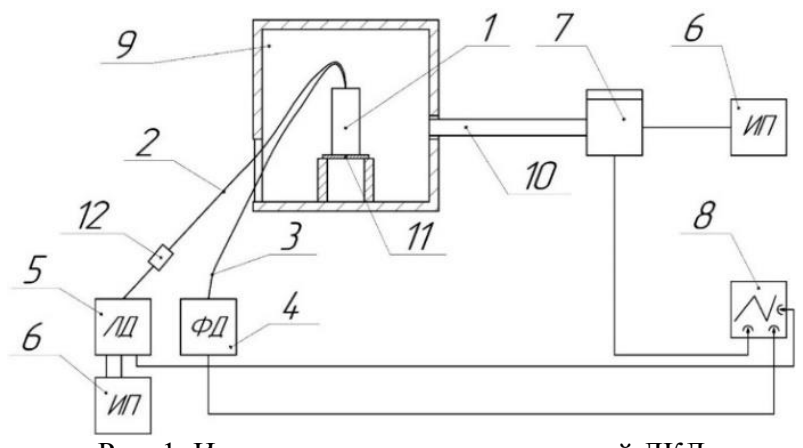

Рис. 1. Измерительная схема испытаний ЛКД 1 - лазерный детонатор, 2 - световод инициирующий, 3 - световод регистрирующий, 4,7 - фотодиоды, 5 - лазерный диод, 6 - источник питания, 8 - осциллограф двулучевой Agilent 1000 Series DSO 1022 A, 9 - защитная камера, 10 - световод измерительный, 11- свинцовая пластина, 12 - коннектор

Запуск осциллографа осуществлялся при подаче лазерного излучения от драйвера или непосредственно от фотодиода 4 от отраженного света инициирующего световода. В первом случае перед 
фотодиодом 4 размещался светофильтр, предотвращающий фиксацию света от инициирующего световода. В этом случае фотодиод 4 фиксировал зажигание ВB, а время от момента запуска осциллографа до электрического сигнала вспышки, генерируемого фотодиодом, соответствовало времени задержки зажигания (воспламенения). На рис. 2 приведена типичная осциллограмма процесса лазерного инициирования ЛКД.

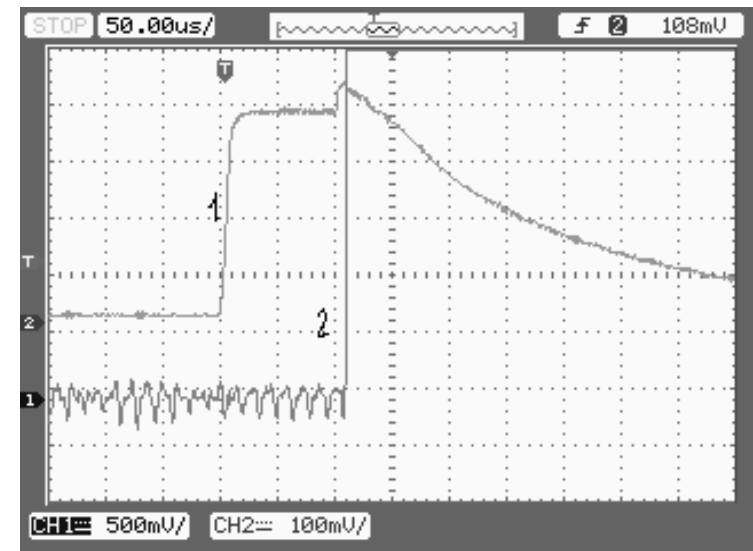

Рис. 2. Типичная осциллограмма процесса лазерного инициирования ВЭМ

1 - сигнал с измерительного световода (фотодиода 4);

2 - сигнал с фотодиода 7 после разрушения оболочки (выход свечения)

При инициировании ТНРС, модифицированного астраленом, от мощности излучения 10 Вт время срабатывания ЛКД уменьшается в 40 раз по сравнению с аналогичными испытаниями на штатном ТНРС одинаковой дисперсности. Сравнительные осциллограммы приведены процесса лазерного инициирования и ТНРС-М и ТНРС приведены на рис. 3.

Результаты сравнительных испытаний по лазерному инициированию ВЭМ штатных и модифицированных астраленом в конструкции ЛКД (при содержании астралена в составе $0,5 \%$ масс.) представлены в таблице. В ЛКД, где в качестве светочувствительного вещества использовали ТНРСМ или ТНРС, на тонкий слой ТНРС запрессовывали азид свинца (АС) совместно с гексогеном. В ЛКД на основе ТЭН и НКТ реализовывался переход горения в детонацию. Инициирующую способность макета ЛКД оценивали по пробитию свинцовой пластины и по глубине отпечатка на стальной плите $[14,15]$.

Наблюдаемый эффект повышения чувствительности модифицированных астраленом ВЭМ, представленных в таблице, увеличивается для ТЭН в 5000 раз, для НКТ более 100 и для ТНРС в 20 раз. Время работы ЛКД уменьшается в 40-100 раз.

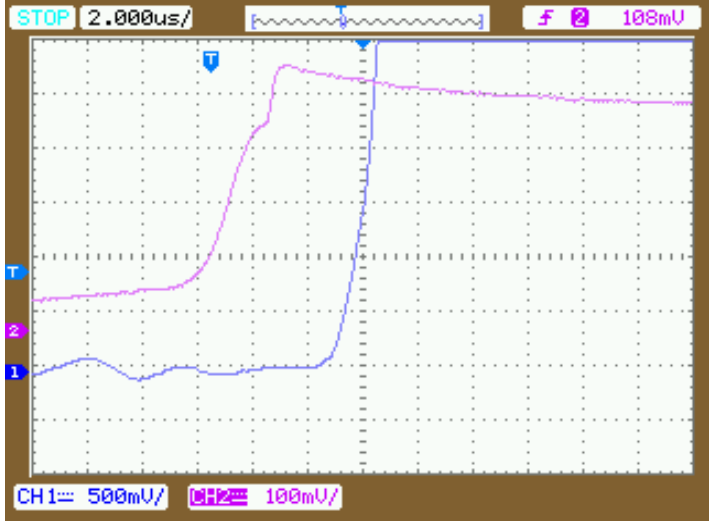

a)

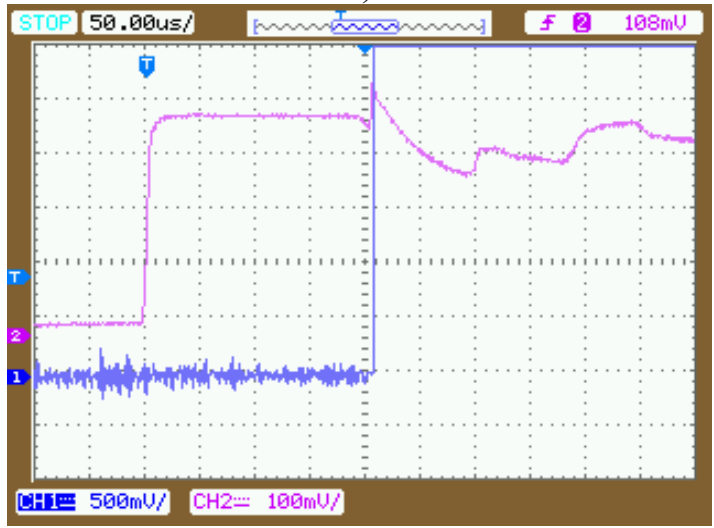

б)

Рис. 3. Осциллограммы процесса лазерного инициирования THPC-M (a), THPC (б)

Таблица

Результаты сравнительных испытаний по лазерному инициированию ВЭМ штатных и модифицированных астраленом в конструкции ЛКД

\begin{tabular}{|c|c|c|c|c|}
\hline \multirow[b]{2}{*}{$\begin{array}{l}\text { Основ- } \\
\text { ное ВВ }\end{array}$} & \multirow{2}{*}{$\begin{array}{c}\text { Порог } \\
\text { плотно- } \\
\text { сти } \\
\text { мощно- } \\
\text { сти ЛИ } \\
\text { штат- } \\
\text { ного ВВ, } \\
\text { Вт/см² }\end{array}$} & \multirow{2}{*}{$\begin{array}{c}\text { Порог } \\
\text { плотно- } \\
\text { сти мощ- } \\
\text { ности ЛИ } \\
\text { ВВ, мо- } \\
\text { дифици- } \\
\text { рованных } \\
\text { астрале- } \\
\text { ном, } \\
\text { Вт/см² }\end{array}$} & \multicolumn{2}{|c|}{$\begin{array}{c}\text { Время срабаты- } \\
\text { вания ЛКД при } \\
\text { мощности ЛИ } \\
10 \text { Вт, мкс }\end{array}$} \\
\hline & & & $\begin{array}{c}\text { штат- } \\
\text { ного }\end{array}$ & $\begin{array}{c}\text { моди- } \\
\text { фици- } \\
\text { рован- } \\
\text { ного } \\
\text { астра- } \\
\text { леном }\end{array}$ \\
\hline ТЭН & $1,5 \cdot 10^{9}$ & $0,3 \cdot 10^{6}$ & $\begin{array}{l}\text { Более } \\
10000\end{array}$ & 300 \\
\hline HKT & $2,5 \cdot 10^{6}$ & $0,02 \cdot 10^{6}$ & 2500 & 20 \\
\hline $\begin{array}{c}\text { THPC- } \\
\text { AC }\end{array}$ & $0,2 \cdot 10^{6}$ & $0,01 \cdot 10^{6}$ & 200 & $5 ; 20 *$ \\
\hline
\end{tabular}

*- крупнодисперсный

\section{ВЫВОДЫ}

На основе результатов проведенных исследований можно сделать следующие выводы:

1. Введение углеродных наноразмерных частиц фуллероидного типа (астралена) в такие ВЭМ, как ТЭН, НКТ и ТНРС, относящиеся к разным 
классам ВВ, способствует значительному увеличению чувствительности к лазерному излучению с длиной волны излучения 976 нм.

2. Значительное увеличение чувствительности к лазерному излучению связано не только за счет поглощения квантов излучения наночастицами астралена с образованием «горячих точек», но и, по-видимому, со специфическим механизмом, свойственным для фуллероидных наночастиц

\section{ЛИТЕРАТ У Р А}

1. Aleksandrov E.I., Voznyuk A.G., Tsipilev V.P. Effect of absorbing impurities on explosive initiation by laser light. Combustion, Explosion and Shock Waves. 1989. V. 25. N 1 P. 1-7. DOI: $10.1007 / \mathrm{bf} 00758226$.

2. Александров Е.И., Вознюк А.Г., Ципилев В.П. Влияние поглощающих примесей на зажигание ВВ лазерным излучением. Физика горения и взрыва. 1989. Т. 25. № 1. С 3-9.

3. Aduev B.P., Belokurov G.M., Nurmukhametov D.R., Nelyubina N.V. Photosensitive material based on PETN mixtures with aluminum nanoparticles. Combustion, Explosion and Shock Waves. 2012. V. 48. N 3. P. 361-366. DOI: $10.1134 / \mathrm{s} 001050821203015 \mathrm{x}$.

4. Белоусов В.П., Белоусова И.М., Беспалов В.Г., Будтов В.П., Григорьев В.А., Данилов О.Б., Жевлаков А.П., Згонник В.Н., Калинцев А.Г., Крысько А.В., Миронова Н.Г., Соснов Е.Н., Пономарев А.Н. Нелинейно-оптические свойства фуллеренсодержащих сред. Оптический журнал. 1997. Т. 64. № 9. С. 83-85.

5. Shames A.I., Katz E.A., Panich A.M., Mogilyansky D., Mogilko E., Grinblat J., Belousov V.P, Belousova I.M., Ponomarev A.N. Structural and magnetic resonance study of astralen nanoparticles. Diamond \& Related Materials. 2008. V. 18. N 2-3. P. 505-510. https://doi.org/10.1016/j.diamond.2008.10.056

6. Белоусов В.П., Белоусова И.М., Будтов В.П., Данилов В.В., Данилов О.Б., Калинцев А.Г., Мак А.А. Фуллерены: структурные, физико-химические и нелинейно-оптические свойства. Оптический журнал. 1997. Т. 64. № 12. С. 3-37.

7. Дидюков А.И., Кулагин Ю.А., Шелепин Л.А., Ярыгина В.Н. Анализ скоростей процессов с участием молекул синглетного кислорода. Квантовая электроника. 1989. Т. 16. № 5. C. $892-904$.

8. Bagrov I.V., Kiselev V.M., Kislyakov I.M., Starodubtsev A.M., Burchinov A.N. Comparative studies of singlet oxygen generation by fullerenes and single- and multilayer carbon nanotubes in aqueous suspensions. Optics and Spectroscopy, 2015. V. 118. N 3. P. 412-416. DOI: 10.1134/s0030400x15030078.

9. Пономарев А.Н. Технологии микромодификации полимерных и неорганических композиционных материалов с использованием нанодисперсных фуллероидных систем. Труды международной конференции. Теория и практика технологий производства изделий из композиционных материалов новых металлических сплавов (ТПКММ): (Москва, 27-30 августа 2003 г.). М.: Знание. 2004. C. 508-518. ISBN 5-07-002978-9. (образование синглетно-возбужденного кислорода при облучении).

3. Результаты работы могут служить основой для разработки безопасных, надежных ЛКД нового поколения для применения в горнодобывающей, нефтегазовой промышленности и других отраслях народного хозяйства.

Авторы заявляют об отсутствии конфликта интересов, требующего раскрытия в данной статье.

\section{REFERENCES}

1. Aleksandrov E.I., Voznyuk A.G., Tsipilev V.P. Effect of absorbing impurities on explosive initiation by laser light. Combustion, Explosion and Shock Waves. 1989. V. 25. N 1. P. 1-7. DOI: $10.1007 / \mathrm{bf00758226.}$

2. Aleksandrov E.I., Voznyuk A.G., Tsipilev V.P. The influence of absorbing additives on explosives ignition by laser radiation. The physics of combustion and explosion. 1989. V. 25. N. 1. P. 3-9.

3. Aduev B.P., Belokurov G.M., Nurmukhametov D.R., Nelyubina N.V. Photosensitive material based on PETN mixtures with aluminum nanoparticles. Combustion, Explosion and Shock Waves. 2012. V. 48. N 3. P. 361-366. DOI: 10.1134/s001050821203015x.

4. Belousov V.P., Belousova I.M., Bespalov V.G., Budtov V.P., Grigor'ev V.A., Danilov O.B., Zhevlakov A.P., Zgonnik V.N., Kalintsev A.G., Krys'ko A.V., Mironova N.G., Sosnov E.N., Ponomarev A.N. Fullerenes: structural, physicochemical and nonlinear optical properties. Opticheskiy Zhurnal. 1997. V. 64. N 9. P. 83-85 (in Russian).

5. Shames A.I., Katz E.A., Panich A.M., Mogilyansky D., Mogilko E., Grinblat J., Belousov V.P, Belousova I.M., Ponomarev A.N. Structural and magnetic resonance study of astralen nanoparticles. Diamond \& Related Materials. 2008. V. 18. N 2-3. P. 505-510. DOI: 10.1016/j.diamond.2008.10.056.

6. Belousov V.P., Belousova I.M., Budtov V.P., Danilov V.V., Danilov O.B., Kalintsev A.G., Mak A.A. Fullerenes: structural, physicochemical and nonlinear optical properties. Journal of Optical Technology. 1997. V. 64. N. 12. P. 3-337.

7. Didyukov A. I., Kulagin Yu. A., Shelepin L. A., Yarygina V.N. Analysis of the rates of processes involving singlet oxygen molecules. Quantum Electronics. 1989. V. 16. N 5. P. 892-3904.

8. Bagrov I.V., Kiselev V.M., Kislyakov I.M., Starodubtsev A.M., Burchinov A.N. Comparative studies of singlet oxygen generation by fullerenes and single- and multilayer carbon nanotubes in aqueous suspensions. Optics and Spectroscopy. 2015. V. 118. N 3. P. 412-416. DOI: 10.1134/s0030400x15030078.

9. Ponomarev A.N. Nanodisperse fulleroid systems assisted technologies of polymeric and inorganic composite materials. Proc. of the International Conference. Theory and practice of technologies of the new metal alloy composite materials ware production (TPKMM): (Moscow, 27-30 august 2003). M.: Znanie. 2004. P. 508-518 (in Russian). ISBN 507-002978-9. 
10. Danilov O.B., Belousova I.M., Mak A.A., Belousov V.P., Grenishin A.S., Kiselev V.M., Krys'ko A.V., Murav'eva T.D., Ponomarev A.N., Sosnov E.N. Fullerene-oxygen-iodine laser (FOIL): physical principles. Proc. of SPIE. V. 5479. Bellingham. 2004. P. 29-34. DOI: $10.1117 / 12.558184$.

11. Brozdnichenko A.N., Ponomarev A.N., Pronin V.P. Rybalko $V$.V. Magnetic properties of multiwall carbon nanotubes and astralenes in strong electric fields. Journal of Surface Investigation. X-Ray, Synchrotron and Neutron Techniques. 2007. V. 1. N 1. P. 110-112. DOI: 10.1134/s1027451007010223.

12. Ponomarev A.N., Figovsky O.L. The giant resonances at disperse interactions of non-metallic particles and examples of the composite materials modified by astralenes. Scientific Israel - Technological Advantages. 2010. V. 12. N. 3. P. 54-57.

13. Дэвид Б., Эдвин Р. Волоконная оптика: теория и практика. перевод с англ. - М: Кудиц-Пресс. 2006. 320 с. ISBN 5-9579-0093-1.

14. Zeman S., Jungova M. Technology of Explosives. Pardubice: University of Pardubice. 2019.

15. Klapötke T.M. Chemistry of High-Energy Materials. 4th ed. Berlin/Boston: Walter de Gruyter GmbH. 2017. 369 P. DOI: 10.1515/9783110536515-202.
10. Danilov O.B., Belousova I.M., Mak A.A., Belousov V.P., Grenishin A.S., Kiselev V.M., Krys'ko A.V., Murav'eva T.D., Ponomarev A.N., Sosnov E.N. Fullerene-oxygen-iodine laser (FOIL): physical principles. Proc. of SPIE. V. 5479. Bellingham. 2004. P. 29-34. DOI: 10.1117/12.558184.

11. Brozdnichenko A.N., Ponomarev A.N., Pronin V.P. Rybalko V.V. Magnetic properties of multiwall carbon nanotubes and astralenes in strong electric fields. Journal of Surface Investigation. X-Ray, Synchrotron and Neutron Techniques. 2007. V. 1. N 1. P. 110-112. DOI: 10.1134/s1027451007010223.

12. Ponomarev A.N., Figovsky O.L. The giant resonances at disperse interactions of non-metallic particles and examples of the composite materials modified by astralenes. Scientific Israel - Technological Advantages. 2010. V. 12. N. 3. P. 54-57.

13. David Bailey, Edwin Wright. Practical Fiber Optics. Amsterdam; London: Elsevier. 2003. P. 288. ISBN 978-0750658003.

14. Zeman S., Jungova M. Technology of Explosives. Pardubice: University of Pardubice. 2019.

15. Klapötke T.M. Chemistry of High-Energy Materials. 4th ed. Berlin/Boston: Walter de Gruyter GmbH. 2017. 369 P. DOI: 10.1515/9783110536515-202.

Поступила в редакииюю (Received) 01.08.2021 Принята к опубликованию (Accepted) 03.09.2021 